\title{
INDOOR AIR TEMPERATURE DISTRIBUTION - AN ALTERNATIVE APPROACH TO BUILDING SIMULATION
}

\begin{abstract}
A. T. Franco and
C. O. R. Negrão

Centro de Educação Tecnológica do Paraná

Departamento Acadêmico de Mecânica

LACIT - Laboratório de Ciências Térmicas

Av. Sete de Setembro, 3165

Centro

80230-901, Curitiba, Paraná, Brasil negrao@cefetpr.br

ABSTRACT

The current paper presents a model to predict indoor air temperature distribution. The approach is based on the energy conservation equation which is written for a certain number of finite volumes within the flow domain. The magnitude of the flow is estimated from a scale analysis of the momentum conservation equation. Discretized two or three-dimensional domains provide a set of algebraic equations. The resulting set of non-linear equations is iteratively solved using the line-by-line Thomas Algorithm. As long as the only equation to be solved is the conservation of energy and its coefficients are not strongly dependent on the temperature field, the solution is considerably fast. Therefore, the application of such model to a whole building system is quite reasonable. Two case studies involving buoyancy driven flows were carried out and comparisons with CFD solutions were performed. The results are quite promising for cases involving relatively strong couplings between heat and airflow.
\end{abstract}

\section{INTRODUCTION}

Usually, building design is based on the hypothesis of uniform indoor properties (such as, temperature, humidity, etc.), assuming that all occupants are subjected to the same condition within a thermal zone (Clarke, 1985). However, in some situations, significant changes of air properties take place in the occupied space, resulting in different perception of comfort at different location. This is only verified after building occupation and operation.

This uniform properties approach might be an acceptable assumption for many problems where the focus is on the long-term energy matters (Hensen, 1991 and Wurtz et al., 1999). This hypothesis, however, is not valid for cases involving relatively strong couplings between heat and airflow or relatively high temperature gradients. Displacement ventilation is a typical example of such case provided the flow is mostly induced by buoyancy forces.

Employed in many thermal-fluid flow problems, Computational Fluid Dynamics (CFD) (Patankar, 1980) has also been applied to the analysis of complex building airflows. For instance, CFD allows computation of indoor air temperature distribution and air velocity gradients and the above shortcomings can be diminished. Nevertheless, a whole year simulation is still prohibited once the number of equations to represent a multi-zone problem is considerably high and their solution is complicated. Besides, the characteristics of indoor air motion are always difficult to identify whether it is locally induced, transitional or fully turbulent. This fact introduces an additional complexity into the modelling which is not completely resolved for building applications.

Recent developments have been made in order to combine the CFD approach and the mixed air model (Negrão, 1998 and Beausoleil-Morrison, et al., 2001). However, such approach is still in its infancy and a whole year simulation applied to multi-store buildings is still prohibited.

Alternatively, a simplified computational model is presented in order to predict indoor air temperature distribution. Two or three-dimensional domains can be discretized in a number of finite volumes and the energy balance is applied to each volume. Buoyancy driven flow is estimated by an scaling analysis (Bejan, 1984) and the computed airflow is imposed in certain volumes. Vargas et al. (2001) introduced this approach and they called it volume element model (VEM). They have solved the air temperature and humidity within an electronic cabinet and validated the results with experimental data. However, their model considers each finite volume as a Bénard cell, which is specific for their case study. In the present study, the energy balances are established according to the geometry and boundary conditions, which is again valid for the current case. Two case studies are investigated: natural convection in a closed cavity and displacement ventilation flow in a room. The results are discussed and compared with a CFD analysis.

\section{MATHEMATICAL MODEL}

The heat transfer processes within an airflow domain can be summarised as, heat diffusion, convection and advection. Considering the flow domain can be divided in a certain number of discrete volumes, as shown in Fig. 1, the energy balance can be applied to each volume. The steady state energy conservation equation for a finite air volume $\mathrm{P}$ can be written as:

$$
\sum_{j=1}^{n} K_{j, P} A_{j}\left(T_{j}-T_{P}\right)+q_{P}^{\prime \prime} V_{P}=0
$$

where $T$ represents the temperature $(\mathrm{K}), V\left(\mathrm{~m}^{3}\right)$ is the volume, $K_{j, P}$ is the conductance coefficient, representing conduction $(k / \Delta x)$, convection $(h)$ or advection 
( $\rho v=\dot{m} / A)$, between volume $j$ and $P\left(\mathrm{~kg} \cdot \mathrm{m}^{-2} \cdot \mathrm{s}^{-1}\right)$ and $q^{\prime,}$, is the heat source within the finite volume per unit of volume $\left(\mathrm{W} / \mathrm{m}^{3}\right)$. The indices $P$ and $j$ are, respectively, the volume under consideration and one of its neighbours. $n$ is the number of $P$ neighbours. Applying the conservation equation for each volume in the domain, a set of algebraic equations arises and must be solved

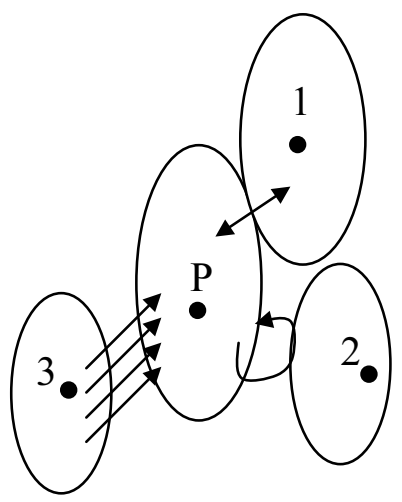

P-1 - Conduction
P-2 - Convection

P-3 - Advection

Figure 1. Heat flow interactions between $\mathrm{P}$ and its neighbours volumes.

Two case studies are established in order to demonstrate the VEM model: natural convection in a 2D closed cavity and 2D displacement ventilation. The mathematical model for each case is presented separately below.

\section{Case 1 - Natural convection in a $2 D$ cavity}

The domain geometry of the 2D cavity is shown in Fig. 2. A heat source of $950 \mathrm{~W}$ is placed in the midway of the room width and all surface temperatures are set to $25^{\circ} \mathrm{C}$. The heat source is not a solid object and therefore does not obstruct the air passage.

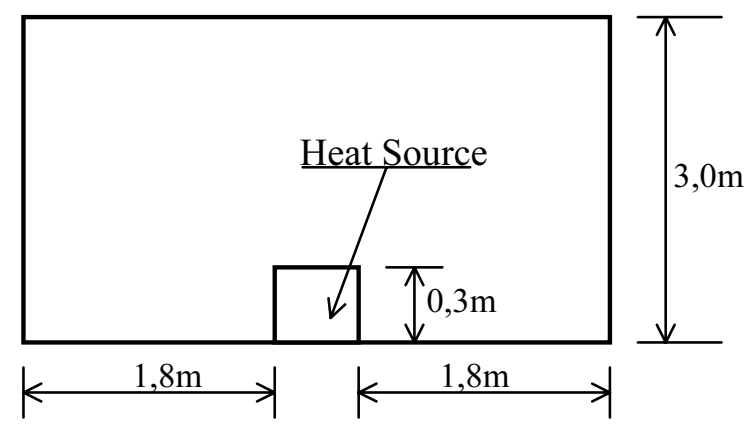

Figure 2. Case study geometry.

One must note that a plume is generated above the source as a result of air heating. Considering the symmetry of the problem, the generated flow must be diverted equally to both sides when the top wall is reached. As the two streams cool down at vertical walls, the flow must

descend close to those walls. The air will mostly flow in a region close to the walls within the boundary layer, as shown in Figure 3. Three regions will thus be considered in the modelling: a fluid flow region at and above the heat source, a fluid flow region close to the walls and a heat diffusion region far from the wall.
After those considerations, the whole domain is divided in a number of finite volumes and an energy balance equation is written for each volume. Three types of cells will be considered, according to the region the cell is placed. Those equations are presented next for each region.

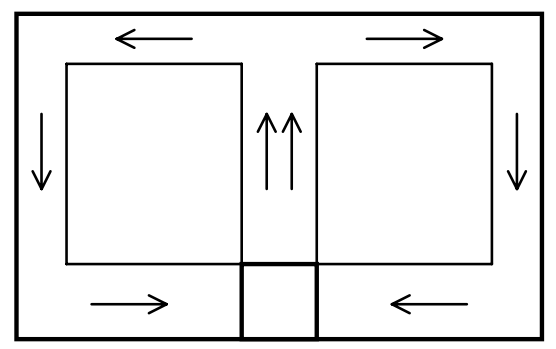

Figure 3. Schematic representation of fluid flow.

\section{Near the wall region.}

Applying Eq. (1) to the cell $P$ close to the left vertical wall, shown in Fig. (4a), results in the following equation:

$$
\dot{m}_{h} c_{p a} T_{H}-\dot{m}_{l} c_{p a} T_{P}+h_{S} A_{s}\left(T_{s}-T_{P}\right)+\frac{k_{n} A_{n}}{\Delta x_{n}}\left(T_{N}-T_{P}\right)=0
$$

where, $T$ is the temperature, $h$ is the convection coefficient, $A$ is the area, $k$ is the air conductivity, $c_{p a}$ is the air specific heat and $\Delta x$ is the distance between two cells. The subscripts $H$ and $N$ represent, respectively, the upper and the right neighbouring cells of $\mathrm{P}$ and the subscripts $h, l, s$ and $n$ refers, respectively, to the interface between $\mathrm{P}$ and $\mathrm{H}, \mathrm{L}, \mathrm{S}$ and $\mathrm{N}$ cells.

One should note that the first and second terms of Eq. (2) represent advection, the third is the convection at the wall and the last one, diffusion of heat. Equation (2) can be applied to any cell close to the wall, however, the direction of flow must be taken into account. Note that advection conductance is represented by $\dot{m}(\rho v A)$.

\section{Heat source region}

Applying the energy conservation equation to cell $P$ in Fig. 4b, the following equation is obtained:

$$
\dot{m}_{c} c_{p a} T_{L}-\dot{m}_{n} c_{p d} T_{P}+\frac{k_{s} A_{s}}{\Delta x_{s}}\left(T_{S}-T_{P}\right)+\frac{k_{n} A_{n}}{\Delta x_{n}}\left(T_{N}-T_{P}\right)=0
$$

Note that advection takes place at vertical direction and diffusion in the horizontal direction.

\section{Middle of the room region}

The energy conservation applied to the middle cells in Fig. (4c) results in the equation:

$$
\frac{k_{l} A_{l}}{\Delta z_{l}}\left(T_{L}-T_{P}\right)+\frac{k_{h} A_{h}}{\Delta z_{h}}\left(T_{H}-T_{P}\right)+\frac{k_{s} A_{s}}{\Delta x_{s}}\left(T_{S}-T_{P}\right)+\frac{k_{n} A_{n}}{\Delta x_{n}}\left(T_{N}-T_{P}\right)=0
$$

In this part of the domain, only diffusion of heat is considered to take place. 


\section{TECNOLOGIA/TECHNOLOGY}

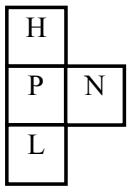

(a)

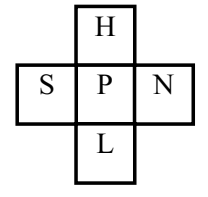

(b)

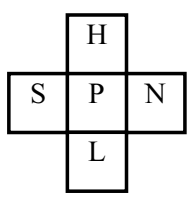

(c)
Figure 4. Dicretization scheme. Cell $P$ and its neighbours: (a) close to the wall, (b) at/above heat source, and (c) in the middle of the domain.

\section{Convection coefficients}

The convection heat transfer coefficients can be obtained from the literature (Clarke, 1985 and Alamdari and Hammond, 1983) and these are usually dependent on the air temperature and flow characteristics.

$$
h=\left\{\left[a\left(\frac{\Delta T}{d}\right)^{p}\right]^{m}+\left[b(\Delta T)^{q}\right]^{m}\right\}^{1 / m}
$$

where $a, b, p, q$ and $m$ are given in Table 1 .

For horizontal surfaces undergoing downward heat flow the natural convective heat transfer coefficient is given by:

$$
h=0.6\left(\frac{\Delta T}{d}\right)^{1 / 5}
$$

where $\Delta T$ is the difference of temperature between the air and the surface. For vertical surfaces, the characteristic dimension $d$ is given by the surface height, whereas for horizontal surfaces the characteristic dimension is the hydraulic diameter, found from

$$
d=\frac{4 A}{P}
$$

where $A$ is the surface area and $P$ is the perimeter length.

Table 1. Empirical coefficients for Eq. (5) from Alamdari and Hammond (1983).

\begin{tabular}{|l||c|c|c|c|c|}
\hline $\begin{array}{l}\text { Surface } \\
\text { topology }\end{array}$ & $\mathrm{a}$ & $\mathrm{b}$ & $\mathrm{p}$ & $\mathrm{q}$ & $\mathrm{m}$ \\
\hline \hline Vertical & 1.5 & 1.23 & $1 / 4$ & $1 / 3$ & 6 \\
\hline Horizontal & 1.4 & 1.63 & $1 / 4$ & $1 / 3$ & 6 \\
\hline
\end{tabular}

\section{Mass flow rates}

Bejan (1984) has proposed a scale analysis based on momentum, energy and mass conservation equations for natural convection at vertical walls. From his analysis, the order of magnitude of the air velocity at the boundary layer can be estimated as:
A. T. Franco and C. O. Negrão Indoor Air Temperature...

where $\operatorname{Pr}$ is the air Prandtl number and $R a$ is the Rayleigh Number, defined as $R a=\frac{g \beta \Delta T H^{3}}{\alpha v}, g$ is the gravitational constant, $\beta$ is the expansion coefficient, $H$ is the plate height (in the current work, the wall height), $\alpha$ and $v$ are, respectively, the thermal and hydrodynamic diffusivities. The $\Delta T$ is the difference between the wall temperature and the air temperature outside the boundary layer.

Eq. (8) is employed to estimate the air velocity at the plume. This vertical velocity is considered uniform to all cells at and above the heat source. The Rayleigh number is based on the domain height and on the maximum temperature difference within the domain (maximum air temperature at the heat source minus the wall temperature).

The mass flow rate is computed based on the vertical air velocity and on the area of the cells above the source. The airflow close to the horizontal and vertical walls is half of the flow generated at the plume and this circulates at the row of cells closer to the walls.

As the air flow and convection coefficients are dependent on the air temperature and vice-versa, an iterative procedure is necessary to solve the set of algebraic equations.

\section{Case 2 - Displacement ventilation in a room}

The present case is similar to the previous one. As shown in Fig. 5, it differs only by the inlet and outlet openings. The same heat source of $950 \mathrm{~W}$ is placed in the midway of the room width and all surface temperatures are set to $22^{\circ} \mathrm{C}$.

Air is supplied to the cavity by the openings $(0.3 \mathrm{~m}$ high $)$ at the floor level with a temperature of $T_{i}=20^{\circ} \mathrm{C}$ and speed of $V_{i}=0.2 \mathrm{~m} / \mathrm{s}$. This low speed flow is directed to the centre of the room and rises together with plume flow. The incoming flow leaves the room through the top openings $(0.3 \mathrm{~m}$ high) while the remaining flow forms two descending streams near the vertical walls. The re-circulating streams will mostly flow in a region close to the walls within the boundary layer, as shown in Fig. 6. Four regions will thus be considered in the modelling, three fluid flow regions (near the inlet and outlets, at and above the heat source and close to the walls) and a heat diffusion region far from the walls.

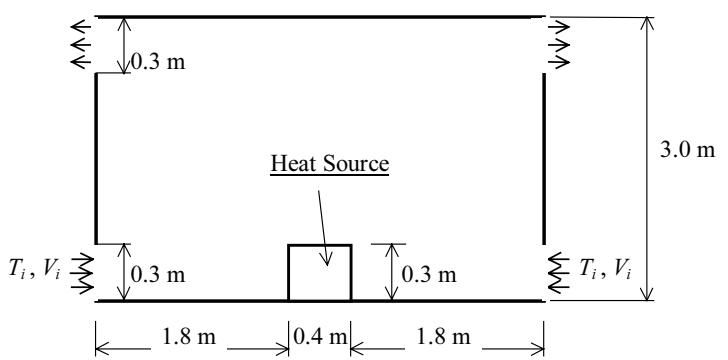

Figure 5. 2D Displacement ventilation geometry.

$$
v=\frac{\alpha}{H}(\operatorname{RaPr})^{1 / 2} \quad \text { if } \quad \operatorname{Pr}<1
$$




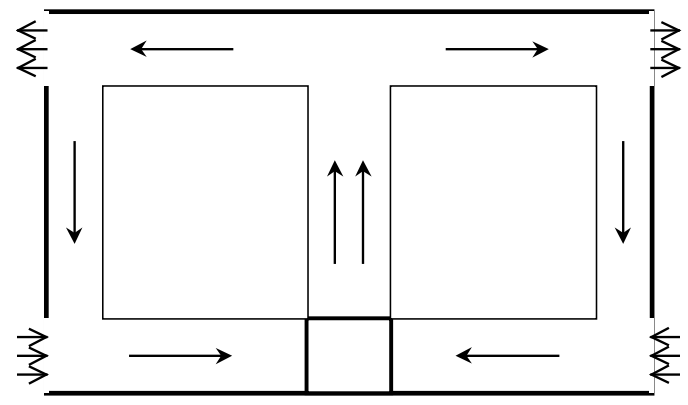

Figure 6. Schematic representation of fluid flow.

Again, the whole domain is divided in a number of finite volumes (cells) and an energy balance equation is written for each volume. Four types of cells will be considered, according to the region they are placed (Fig. 7). Three of them (near the wall, heat source and middle of the room regions) employ the above Eqs. (2), (3) e (4). Only the equation for the openings regions needs to be written.

\section{Near the opening region.}

Consider the cell $P$ close to the bottom left entrance, shown in Fig. 7a. Applying Eq. (1) to this cell:

$$
\dot{m}_{h} c_{p a} T_{H}+h_{l} A_{l}\left(T_{l}-T_{P}\right)-\dot{m}_{n} c_{p a} T_{P}+\dot{m}_{i} c_{p a} T_{i}=0
$$

where, the subscript $i$ refers to the inlet. A similar balance can be applied to the other inlet and to the outlets. (a)

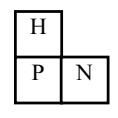

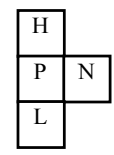

(b)

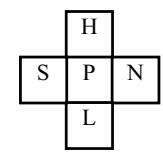

(c)

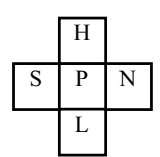

(d)
Figure 7. Discretization scheme. Cell $P$ and its neighbours:

(a) at the inlet supply, (b) close to the wall, (c) at/above heat source and (d) in the middle of the domain.

Convection coefficients and mass flow rates are estimated as described in the previous section. The incoming flow, however, is added to the plume flow created by the heat source.

\section{METHOD OF SOLUTION}

The application of Eqs. (2) to (4) and (9) to all finite volumes in the domain originates a set of nonlinear algebraic equations:

$$
A_{P} T_{P}=A_{s} T_{S}+A_{n} T_{N}+A_{l} T_{L}+A_{h} T_{H}+S_{P}
$$

where $A^{\prime}$ s are the coefficients that depend on the mass flow rate, convection coefficients and air conductivity. The set of algebraic Eqs. (10) is solved by the interactive line-by-line Thomas Algorithm (Patankar, 1980).

\section{RESULTS}

Case 1 - Natural convection in a 2D closed cavity
A. T. Franco and C. O. Negrão Indoor Air Temperature...

The geometry of Fig. (2) is divided in $11 \times 12$ finite volumes and the temperature distribution is shown in Fig. 8. The computational time to achieve the converged solution was minimal. The velocity estimated by Eq. (8) is in the order of $0.7 \mathrm{~m} / \mathrm{s}$ and the convection coefficients are computed from Eqs. (5) and (6). As expected, the highest temperature in the cavity is within the heat source. Also, the isotherms indicate the imposed circulation of flow. The heat flows at the walls are $201.9 \mathrm{~W}, 201.9 \mathrm{~W}, 254.0 \mathrm{~W}, 292.3 \mathrm{~W}$, respectively, at the south, north, low and high walls. The temperature is stratified and the difference of temperature from top to bottom walls reaches $1.7^{\circ} \mathrm{C}$, as shown in Table 2 . Based on the above heat flows and on the convection coefficients, an average air temperature of $33.5^{\circ} \mathrm{C}$ can be computed. This is the result of the mixed flow model that is not representative of the whole room temperature (see Table 2).

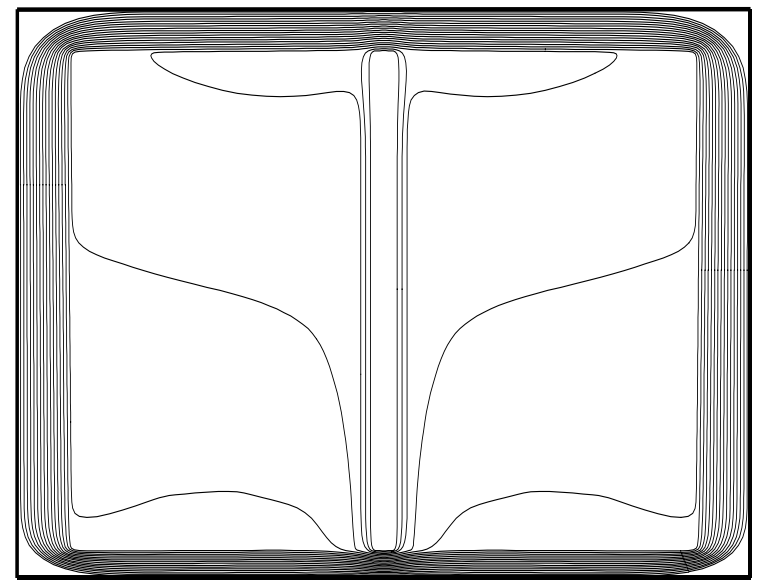

Figure 8. Temperature distribution within the cavity.

In order to corroborate the results, an intermodel comparison was conducted. The CFD modelling was considered and the Flotherm ${ }^{\text {TM }}$ (2001) package was employed as the base model. The Flotherm ${ }^{\text {TM }}$ model was built for the geometry of Fig. (2).

The Flotherm ${ }^{\mathrm{TM}}$ (2001) solves the steady NavierStokes and energy equations and the turbulent flow is modelled by the Turbulent k- $\varepsilon$ Revised Model of Flotherm $^{\mathrm{TM}}$, which is an enhancement of the Launder and Spalding (1974) k- $\varepsilon$ standard model. Flotherm ${ }^{\text {TM }}$ model claims to provide a better estimate of gradients near the walls. The equations are discretized by the SIMPLE method by Patankar (1980). The employed Cartesian mesh of $164 \times 112$ points $(18,368$ control volumes $)$ is refined where the higher gradients are expected; namely, close to the source and walls. A SUN Ultra Enterprise 450 Workstation (2 SUNW processors, 296MHz, 768Mbytes RAM) was employed in the CFD simulation. The necessary CPU time was about $10 \mathrm{~min}$.

Figure 9a shows the isotherms obtained by Flotherm $^{\text {TM }}$. As expected, the highest temperatures take place at the heat source and the highest temperature gradients are close to the walls. Figure 10 illustrates the Flotherm ${ }^{\text {TM }}$ velocity field which states a clear flow above the source and close to the walls. As foreseen, the velocities in the central region of the room assume low values and definitely only diffusion takes place in that region. 


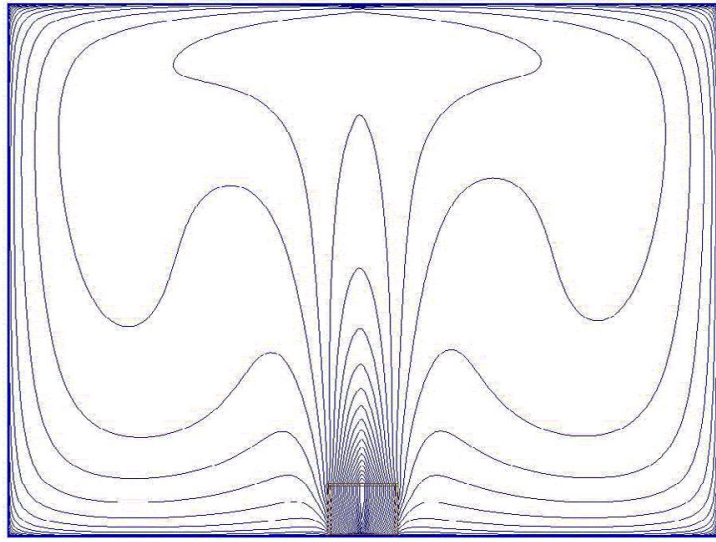

(a)

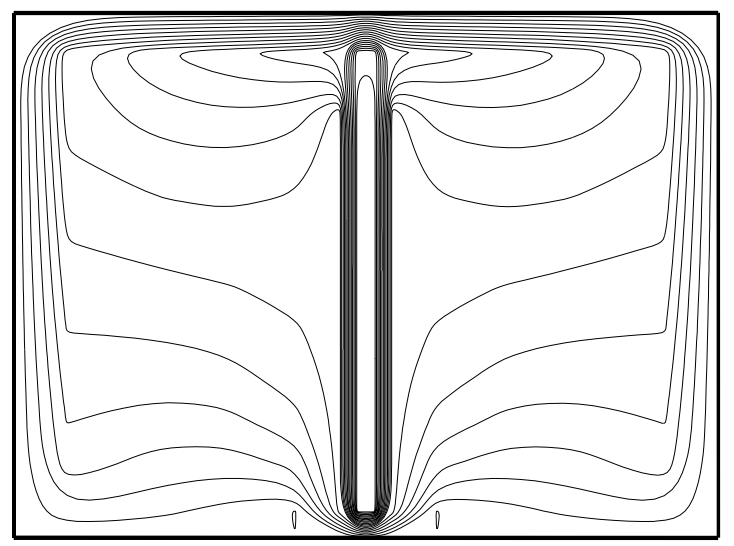

(b)

Figure 9. Comparison of isotherms produced by (a) Flotherm ${ }^{\mathrm{TM}}$ and (b) the current model.

With the purpose to compare the models isotherms, some information necessary for VEM was obtained directly from the Flotherm ${ }^{\text {TM }}$ results. The plume velocity was acquired from the Flotherm ${ }^{\mathrm{TM}}$ results. Fig. 10 shows it is in the order of $0,3 \mathrm{~m} / \mathrm{s}$. The width/height of the first row of cells close to the wall was also estimated from Fig. 10 (width of cells near the vertical walls $=0,6 \mathrm{~m}$; height of cells near the top wall $=0,45 \mathrm{~m}$ and near the bottom wall $=0,3 \mathrm{~m})$. The convection heat flow at the walls $(\mathrm{Qs}=\mathrm{Qn}=205,2 \mathrm{~W}, \mathrm{Ql}=243 \mathrm{~W}, \mathrm{Qh}=296,4 \mathrm{~W})$ was computed based on the Flotherm ${ }^{\mathrm{T} M}$ results and they were imposed at the walls.

Figure 9 shows that the isotherms of Flotherm ${ }^{\text {TM }}$ are quite similar to those of the current model. The range of temperature within the cavity varies from 25.0 to $34.7^{\circ} \mathrm{C}$ in the VEM results and from 25.5 to $32.4^{\circ} \mathrm{C}$ in the CFD results. Both present a plume above the heat source. Also, the highest temperature gradients are near the walls and close to the heat source (the isotherms are closest to each other) in both cases. Nevertheless, the largest difference between the profiles is in the plume, which is explained by the different velocities in that region. On one hand, the CFD velocity distribution (Fig. 10) shows that the plume width increases as the flow rises, and on the other hand, an uniform velocity is imposed in all cells above the heat source. An enhancement on the plume modelling can definitely approximate the CFD and the current model results.
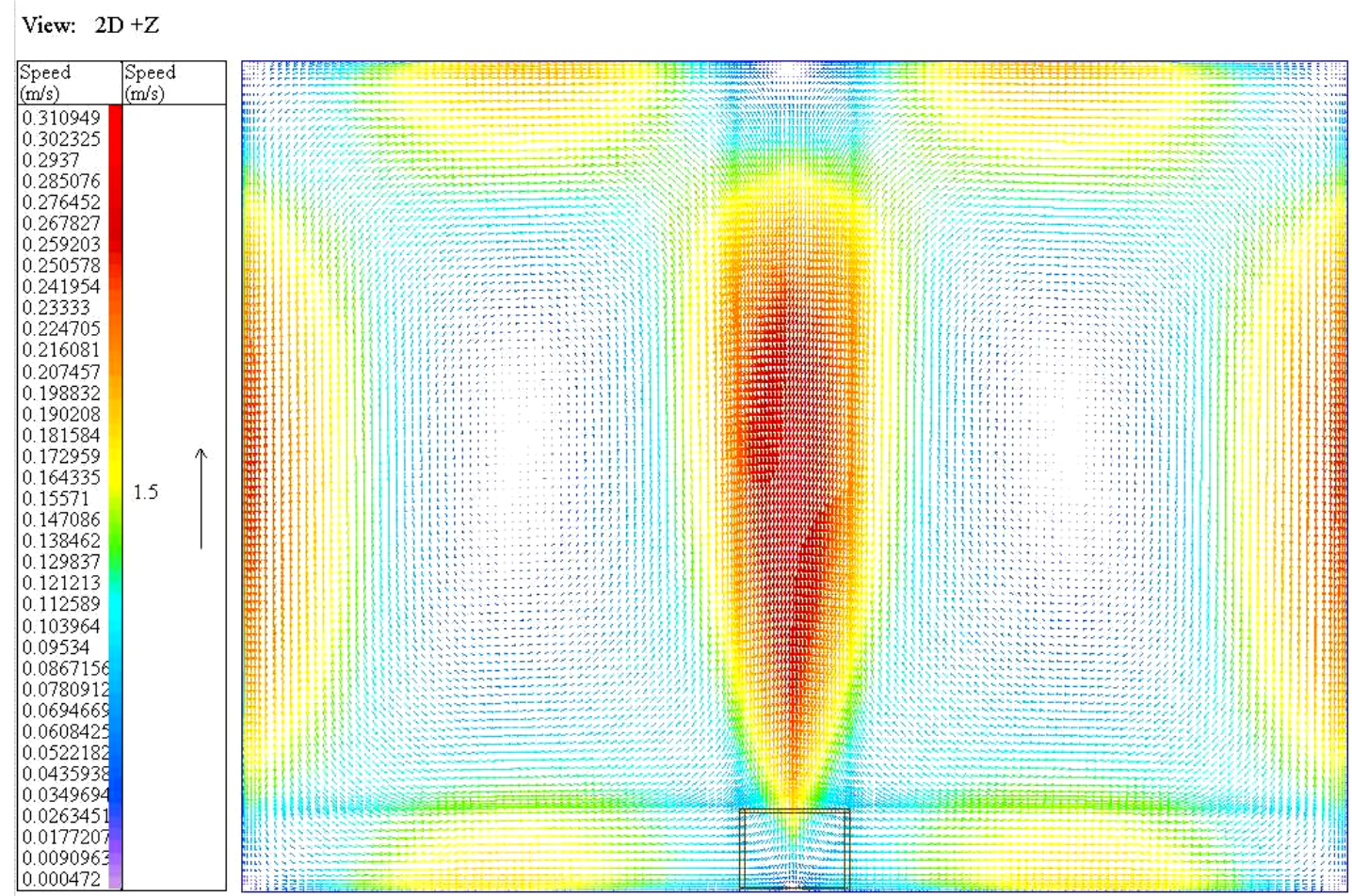

Figure 10 . The velocity field obtained with the k- $\varepsilon$ revised turbulence model of Flotherm ${ }^{\mathrm{T} M}$.

\section{Case 2 - 2D Displacement ventilation in a room}

The geometry of Fig. 5 is divided in $12 \times 11$ finite volumes and the temperature distribution is shown in Fig.
11. The results showed to be insensitive for a greater number of finite volumes and the computational time to achieve the converged solution was minimal. The velocity 
estimated by Eq. (8) is in the order of $0.7 \mathrm{~m} / \mathrm{s}$. The convection coefficients are computed by Eqs. (5) and (6) and the heat flux is based on the difference of wall temperature and the temperature of the cells nearest to the wall. As expected, the highest temperature in the cavity is within the heat source. Also, the isotherms indicate the imposed flow circulation, the outgoing flow in the upper slots, and cold incoming flow at the lower slots. The temperature is stratified, as supposed to be in displacement ventilation, and the difference of temperature from top to bottom walls is $2.0^{\circ} \mathrm{C}$, as shown in Table 3 . The average air temperature evaluated by the mixed flow model is $26.0^{\circ} \mathrm{C}$, which is not representative of the whole room temperature; temperature varies from 24.2 to $27.1^{\circ} \mathrm{C}$.

Table 2. Temperature within the closed cavity in ${ }^{\circ} \mathrm{C}$

\begin{tabular}{|c|c|c|c|c|c|c|c|c|c|c|c|c|}
\hline 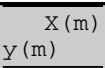 & 0.300 & 0.800 & 1.200 & 1.600 & 1.850 & 1.950 & 2.050 & 2.150 & 2.400 & 2.800 & 3.200 & 3.700 \\
\hline 2.775 & 33.76 & 34.07 & 34.19 & 34.31 & 334.43 & 35.37 & 35.37 & 34.43 & 34.31 & 34.19 & 34.07 & 33.76 \\
\hline 2.425 & 33.69 & 33.85 & 33.91 & 33.86 & 33.55 & 35.44 & 35.44 & 33.55 & 33.86 & 33.91 & 33.85 & 33.69 \\
\hline 2.175 & 33.62 & 33.73 & 33.76 & 33.70 & 33.55 & 35.44 & 35.44 & 33.55 & 33.70 & 33.76 & 33.73 & 33.62 \\
\hline 1.925 & 33.55 & 33.62 & 33.65 & 33.62 & 33.55 & 35.44 & 35.44 & 33.55 & 33.62 & 33.65 & 33.62 & 33.55 \\
\hline 1.675 & 33.48 & 33.53 & 33.56 & 33.56 & 33.55 & 35.44 & 35.44 & 33.55 & 33.56 & 33.56 & 33.53 & 33.48 \\
\hline 1.425 & 33.41 & 33.44 & 33.48 & 33.52 & 33.55 & 35.44 & 35.44 & 33.55 & 33.52 & 33.48 & 33.44 & 33.41 \\
\hline 1.175 & 33.34 & 33.35 & 33.39 & 33.47 & 33.55 & 35.44 & 35.44 & 33.55 & 33.47 & 33.39 & 33.35 & 33.34 \\
\hline 0.925 & 33.27 & 33.25 & 33.29 & 33.41 & 33.55 & 35.44 & 35.44 & 33.55 & 33.41 & 33.29 & 33.25 & 33.27 \\
\hline 0.675 & 33.20 & 33.14 & 33.15 & 33.30 & 33.55 & 35.44 & 35.44 & 33.55 & 33.30 & 33.15 & 33.14 & 33.20 \\
\hline 0.425 & 33.14 & 32.99 & 32.97 & 33.09 & 33.55 & 35.44 & 35.44 & 33.55 & 33.09 & 32.97 & 32.99 & 33.14 \\
\hline 0.150 & 32.90 & 32.80 & 32.70 & 32.60 & 33.55 & 35.44 & 35.44 & 33.55 & 32.60 & 32.70 & 32.80 & 32.90 \\
\hline
\end{tabular}

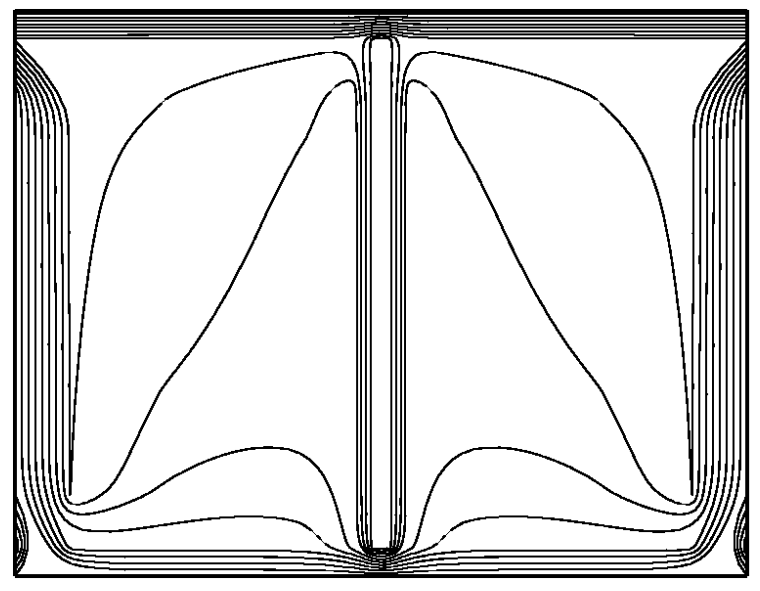

Figure 11. Temperature distribution inside the cavity.

A sensibility analysis was conducted by changing the wall temperatures to $25^{\circ} \mathrm{C}$. Figure 12 shows that the temperature gradient reduce at the walls and increase at the inlets

Again, in order to corroborate the results, an inter-model comparison was conducted. Surface temperatures were changed to $21.0^{\circ} \mathrm{C}$. The CFD modelling was considered and the Flotherm ${ }^{\mathrm{TM}}$ (2001) package was employed as the base model. The Flotherm ${ }^{\text {TM }}$ model was built for the geometry of Fig. 5. The necessary CPU time is in the order of $30 \mathrm{~min}$.

Figure 13 illustrates the Flotherm ${ }^{\mathrm{T} M}$ velocity field which states a clear flow close to the floor, ceiling and above the source and a smaller recirculation flow. As foreseen, the velocities in the central region of the room assume low values and definitely only diffusion takes place in that region.

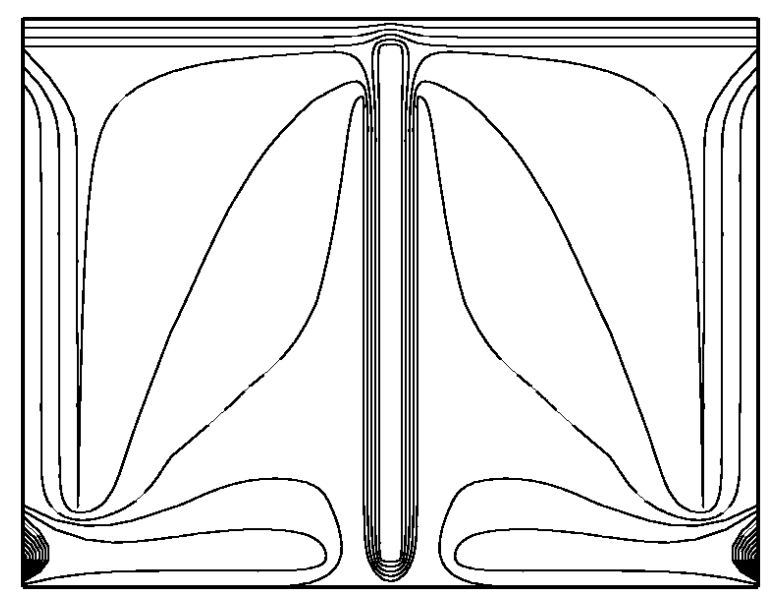

Figure 12. Temperature distribution for wall temperatures equal to $25^{\circ} \mathrm{C}$.

With the purpose to compare the isotherms of the models, some information necessary for VEM was obtained directly from the Flotherm ${ }^{\mathrm{TM}}$ results. The plume velocity (Fig. 13)acquired from the Flotherm ${ }^{\mathrm{TM}}$ results is in the order of $0.3 \mathrm{~m} / \mathrm{s}$. The width/height of the first row of cells close to the wall was also estimated from Fig. 13 (width of cells near the vertical walls $=0.25 \mathrm{~m}$; height of cells near the top and bottom walls $=0.3 \mathrm{~m}$ ).

Figure 14 shows that the isotherms of Flotherm ${ }^{\text {TM }}$ are quite similar to those of the current model. The range of temperature within the cavity varies from $21.0^{\circ} \mathrm{C}$ to $26^{\circ} \mathrm{C}$ in the VEM results and from $20.0^{\circ} \mathrm{C}$ to $25.2^{\circ} \mathrm{C}$ in the CFD results. Both present a plume above the heat source. Also, the highest temperature gradients are near the heat source (the isotherms are closest to each other). Once again, the largest difference between the profiles is in the plume, which is explained by the different velocities in that region. 


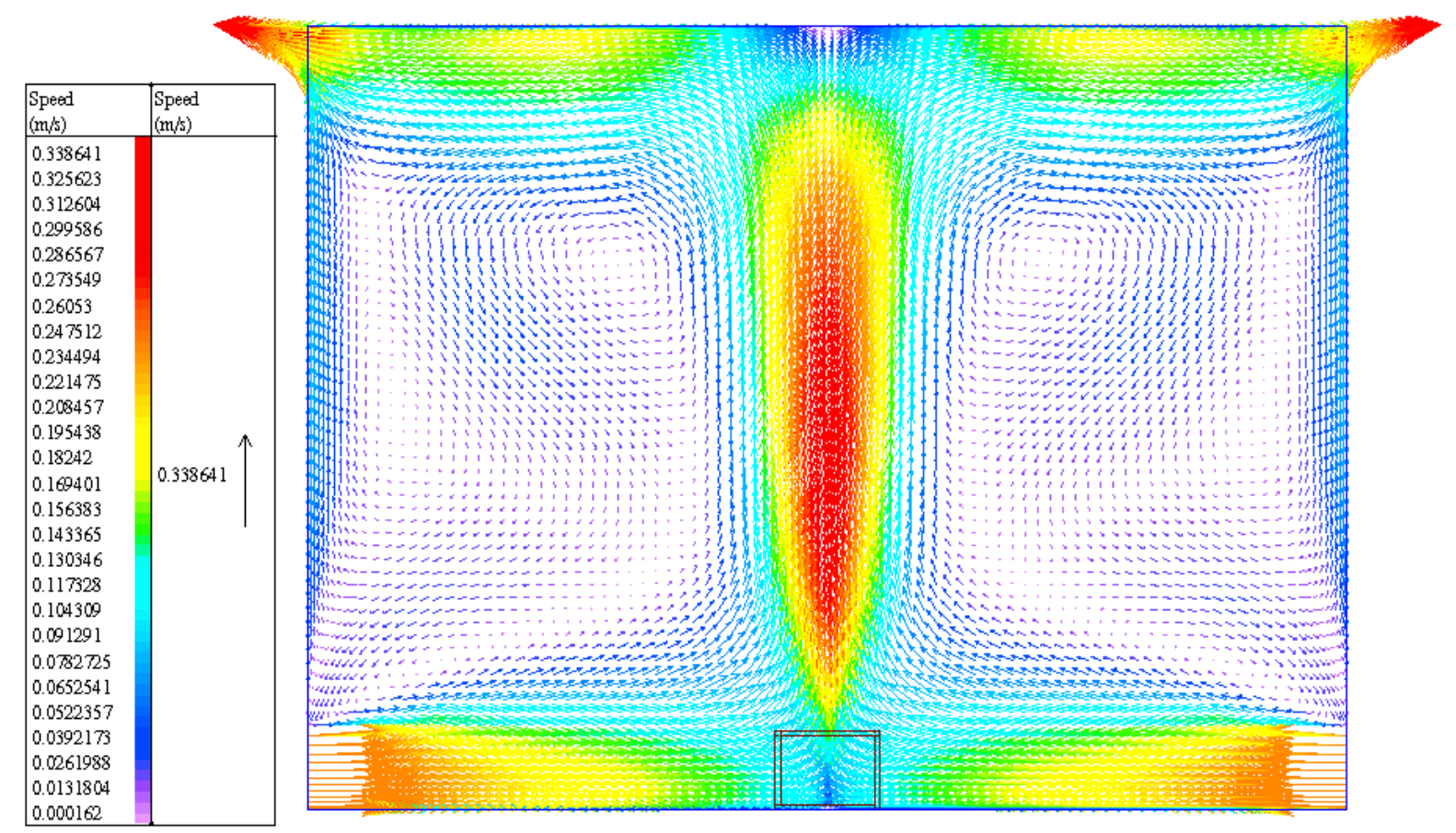

Figure 13 . The velocity field obtained with the k- $\varepsilon$ revised turbulence model of Flotherm ${ }^{\mathrm{TM}}$.

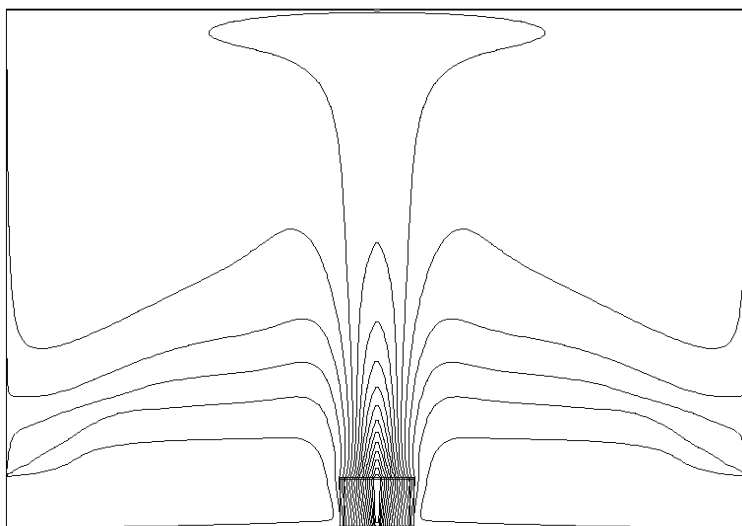

(a)

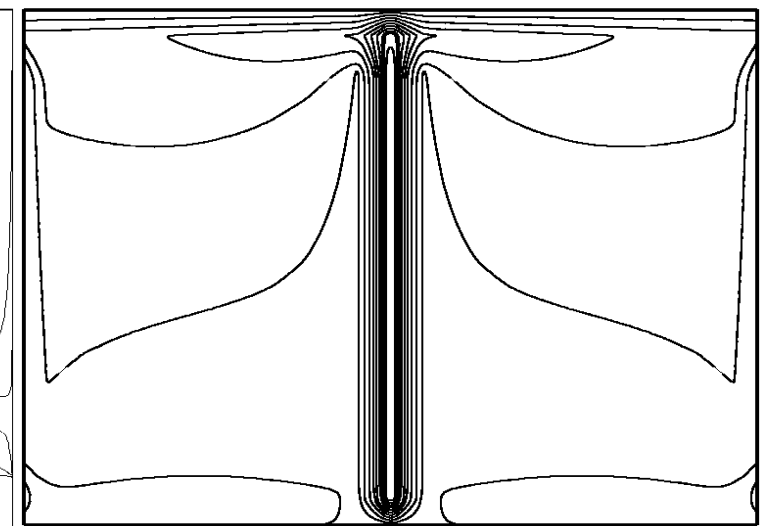

(b)

Figure 14. Comparison of isotherms produced by (a) Flotherm ${ }^{\mathrm{TM}}$ and (b) the current model.

\section{DISCUSSION AND CONCLUSIONS}

The current paper presents a simplified numerical model to predict indoor temperature distribution based on the discretization of the energy equation and on the scale analysis of the momentum conservation equation. A comparison with a CFD model was conducted and the results are quite similar to each other. The current model (volume element model (VEM)) results, however, are obtained with much less computational effort and its application to building simulation programs seems to be very promising.
The model is much dependent on the insight of the modeller/user and information of some more refined methods such as CFD or experimental set-ups can be used to create VEM equations.

As long as most of the differences between CFD and the current model lies on the plume region above the heat source, an introduction of a more accurate plume model in the VEM could improve the comparison.

Experimental and inter-model comparisons still need to be done in order to consolidate the approach. Calibration of Eq. (8) is also necessary. 
Table 3 . Temperature within the open cavity in ${ }^{\circ} \mathrm{C}$

\begin{tabular}{|c||c|c|c|c|c|c|c|c|c|c|c|c|}
\hline $\begin{array}{c}\mathrm{x}(\mathrm{m}) \\
\mathrm{y}(\mathrm{m})\end{array}$ & 0.125 & 0.508 & 1.025 & 1.542 & 1.850 & 1.950 & 2.050 & 2.150 & 2.458 & 2.975 & 3.492 & 3.875 \\
\hline \hline 2.850 & 26.13 & 26.13 & 26.14 & 26.14 & 26.14 & 27.12 & 27.12 & 26.14 & 26.14 & 26.14 & 26.13 & 26.13 \\
\hline 2.567 & 26.11 & 26.05 & 25.95 & 25.73 & 25.17 & 27.12 & 27.12 & 25.17 & 26.73 & 25.95 & 25.05 & 26.11 \\
\hline 2.300 & 26.10 & 25.98 & 25.81 & 25.53 & 25.17 & 27.12 & 27.12 & 25.17 & 25.53 & 25.81 & 25.98 & 26.10 \\
\hline 2.033 & 26.09 & 25.92 & 25.69 & 25.42 & 25.17 & 27.12 & 27.12 & 25.17 & 25.42 & 25.69 & 25.92 & 26.09 \\
\hline 1.767 & 26.07 & 25.85 & 25.59 & 25.34 & 25.17 & 27.12 & 27.12 & 25.17 & 25.34 & 25.59 & 25.85 & 26.07 \\
\hline 1.500 & 26.06 & 25.78 & 25.49 & 25.28 & 25.17 & 27.12 & 27.12 & 25.17 & 25.28 & 25.49 & 25.78 & 26.06 \\
\hline 1.233 & 26.05 & 25.68 & 25.36 & 25.20 & 25.17 & 27.12 & 27.12 & 25.17 & 25.20 & 25.36 & 25.68 & 26.05 \\
\hline 0.967 & 26.03 & 25.54 & 25.20 & 25.10 & 25.17 & 27.12 & 27.12 & 25.17 & 25.10 & 25.20 & 25.54 & 26.03 \\
\hline 0.700 & 26.02 & 25.32 & 24.96 & 24.94 & 25.17 & 27.12 & 27.12 & 25.17 & 24.94 & 24.96 & 25.32 & 26.02 \\
\hline 0.433 & 26.01 & 24.94 & 24.64 & 24.68 & 25.17 & 27.12 & 27.12 & 25.17 & 24.68 & 24.64 & 24.94 & 26.01 \\
\hline 0.150 & 24.22 & 24.21 & 24.20 & 24.19 & 25.17 & 27.13 & 27.13 & 25.17 & 24.19 & 24.20 & 24.21 & 24.22 \\
\hline
\end{tabular}

\section{ACKNOWLEDGMENTS}

The authors would thank the FINEP/CTPETRO for the financial support of the present work.

\section{REFERENCES}

Alamdari F. and Hammond, G. P., 1983, Improved Data Correlation for Buoyancy-Driven Convection in Rooms, Rep. SME $/ \mathrm{J} / 83 / 01$, Cranfield Institute of Technology, Applied Energy Group, Cranfield.

Beausoleil-Morrison, I., Clarke, J. A., Denev, L., MacDonald, I. A., Melikov, A. and Stankov, P., 2001, Further Developments in the Conflation of CFD and Building Simulation, Seventh International IBPSA Conference, Rio de Janeiro, Brazil, pp. 1267-1273.

Bejan, A., 1984, Convection Heat Transfer, John Wiley \& Sons.

Clarke, J. A., 1985, Energy Simulation in Building Design, Adam Hilger.Flotherm ${ }^{\mathrm{TM}}$, Flomerics ${ }^{\circledR}, 2001$,Online Documentation, Version 3.2.

Hensen, J. L. M., 1991, On the Thermal Interaction of Building Strucuture and Heating and Ventilating

System, Technische Universiteit Eindhoven.

Launder, B. E. and Spalding, D. B., 1974, "The Numerical Computation of Turbulent Flow", Computer Methods in Applied Mechanics and Engineering, Vol. 3, pp. 269-289.

Negrão, C. O. R., 1998, "Integration of Computational Fluid Dynamics with Building Thermal and Mass Flow Simulation", Energy and Buildings, Vol 27-2, pp. $155-165$.

Patankar, S. V., 1980, Numerical Heat Transfer and Fluid Flow, Taylor and Francis.

Vargas, J. V. C., 2001, Stanescu, G., Florea, R. and Campos, M. C., "A Numerical Model to Predict the Thermal and Psychrometric Response of Electronic Packages", ASME Journal of Electronic Packaging, Vol. 123(3), pp. 200-210.

Wurtz, E. , Nataf, J. M. and Winkelmann, F., 1999,Two and Three Dimensional Natural and Mixed Convection Simulation using Modular Zonal Models in Buildings, International Journal of Heat and Mass Transfer, vol. 42, pp. 923-940. 